\title{
Range of Motion Outcomes Post Cruciate-Retaining vs Posterior Stabilized Total Knee Arthroplasty: A Retrospective Multi-Centre Cohort Study
}

\author{
Ifran Saleh ${ }^{1}$, J.B Endrotomo Sumargono², Adryan Tanujaya ${ }^{3}$, Oliver Emmanuel Yausep ${ }^{3}$ \\ 1. Department of Orthopaedics and Traumatology, Ciptomangunkusumo Hospital, Jakarta, Indonesia \\ 2. Department of Orthopaedics and Traumatology, St. Carolus Hospital, Jakarta, Indonesia \\ 3. Faculty of Medicine, University of Indonesia, Jakarta, Indonesia
}

\section{ABSTRACT}

Background: The outcomes of Total Knee Arthroplasty (TKA) between posterior cruciate ligament preservation, with cruciate retaining (CR) prostheses and sacrifice, with posterior stabilized (PS) prostheses, are still debated between studies.

Materials and Methods: This study included a total of 144 knees on which TKA was done with either cemented fixed bearing primary CR or PS prostheses. Data analyses were then performed using Independent t-tests, were conducted for the outcomes and possible confounding variables between groups where relevant, and Chi-squared tests for nominal data.

Results: TKA performed on patients aged 65 years or younger, predicted increased intraoperative bleeding volume $(p=0.037)$, pre-operative range of motion (ROM) of less than 90 degrees was a predictor for better improved post-operative ROM ( $p<0.001)$ and PS prostheses is superior to CR in terms of ROM improvement $(p=0.04)$. Nevertheless, both groups achieved similar maximum ROM ( $p=0.308)$.

Conclusion: Greater ROM improvement was significantly higher in the PS prostheses group compared to those receiving CS prostheses, with pre-operative ROM as a possible confounding factor, and the maximum ROM achieved in both groups being similar. Lower age of the operation is also related to increased intraoperative bleeding

Keywords: Total Knee Arthroplasty; Posterior stabilized; Cruciate Retaining; Range of Motion; total knee replacement

Level of Evidence: II

Level of Evide

This is an open access article under the $\underline{\mathrm{CC}-\mathrm{BY}-\mathrm{SA}}$ license.

Article history:

Submission : October $9^{\text {th }}, 2020$

Revision : : December 25 2020

Accepted : December 25 $5^{\text {th }}, 2020$
Corresponding Author:

Oliver Emmanuel Yausep, SKed,

MRes, Cipto Mangunkusumo Hospital, Salemba,

Address: Jl. Pangeran Diponegoro No. 71, RW. 5, Kenari,

Senen, Jakarta Pusat, 10430, Indonesia.

Email: oliveremmanuel@hotmail.com 


\section{Introduction}

Total Knee Arthroplasty (TKA) is one of the most common orthopaedic procedures, with over 500,000 knees replaced between 2012 and 2017 in the United States alone. ${ }^{1}$ The procedure includes resection of the defected articular knee surface and placing a metal and polyethylene prosthetic implant and may involve removal of the posterior cruciate ligament $(\mathrm{PCL})$ in accordance to the type of implant used, cruciate ligamentretaining (CR) prostheses or posterior-stabilized (PS) prostheses. ${ }^{2}$ It is predicted that by 2050 , the number of annual primary TKAs performed in the United States alone would increase by 855 percent from 2012. ${ }^{3}$

To date, the importance of preserving the posterior cruciate ligament in TKA is still debatable. It was traditionally believed that flexion and range of motion is increased if the posterior cruciate ligament is retained as the anatomical femoral rollback and normal knee biomechanics is maintained, hence, more normal physiologic control upon knee flexion. ${ }^{4,5}$ The functional relevance may be found in activities requiring considerable motion such as squatting and climbing stairs. ${ }^{6,7}$ However, the replacement of PCL with a post and cam in PS prostheses was suggested to allow increased range of motion as more posterior femoral translation allows greater clearance over the tibia, hence greater knee flexion. ${ }^{7}$

Recent studies have shown high success rates or both designs, but it is unclear which prostheses would show superior outcomes. ${ }^{8,9}$ The main purpose of this study is to explore the merits of PCL preservation towards range of motion and perioperative outcomes in primary TKA by comparing them based on the prostheses used, $C R$ or PS prostheses.

\section{Materials and Methods}

\section{Patients and Methods}

This is a retrospective multi-center study cohort study that included all patients who had cemented primary TKA for osteoarthritis between the period of 2016-2018 using PS or CR TKA.
Information on the patient, operation, and prostheses used are obtained from the medical records of the hospitals Rumah Sakit Ciptomangunkusumo, Jakarta, Indonesia and Rumah Sakit Santo Carolus, Jakarta. The Ethics Committee of the Faculty of Medicine, University of Indonesia, with regards to the protection of human rights and welfare in medical research, has carefully reviewed and approved of this research. Protocol Number: 19-01-0073

\section{Data Collection}

Patient data to be recorded includes age, gender, body mass index (BMI), indication for TKA, perioperative clinical outcomes and preoperative and postoperative range of motion (ROM) between 6 to 12 months follow up after the operation. The primary outcome of this study is range of motion and the secondary outcomes of this study include perioperative outcomes such as intraoperative blood loss. With regards to the operation itself, data to be observed includes surgical approach of the knee, duration of operation, presenting complications during the operation, and frequency of bleeding. Data for the prostheses only includes the type of the prostheses used. The demographic data will be evaluated between the CR and PS groups.

\section{Statistics}

Independent t-tests are used when comparing the variables between the two groups as well as for possible confounding factors. The Chi-squared test is used to compare nominal data between the two groups. For either cases a $p$ value of less than 0.05 is considered to be statistically significant. The analyses of the data gathered is calculated using the analytical software SPSS.

\section{Results}

A total of 144 operated knees were recorded, and analysed for this research, 24 of which were operated with Cruciate Retaining Prostheses and the remaining 120 knees with Posterior Stabilizing Prostheses, all of which were indicated due to severe osteoarthritis. The 
implants used in this study were all similar, produced by PFC Sigma, and surgical approaches were all standardized to medial parapatellar. There were no recorded presences of bone defects, preoperative recurvatum or flexion contracture.

The data recorded in each medical record varied in outcomes reported, hence the comparison was performed using parameters found in all medical records. This included the age, gender, intraoperative bleeding volume, and Range of Motion (ROM). There were no reported presenting complications during the operation. (Table I)

\begin{tabular}{llll}
\multicolumn{4}{c}{ Table I. Baseline Characteristics } \\
\hline & $\begin{array}{l}\text { CR Group } \\
(\mathbf{n}=\mathbf{2 4})\end{array}$ & $\begin{array}{l}\text { PS Group } \\
(\mathbf{n}=\mathbf{1 2 0})\end{array}$ & p-Value \\
\hline $\begin{array}{l}\text { Age (years) } \\
\text { Sex (male:female) }\end{array}$ & $64.88 \pm 13.185$ & $67.63 \pm 8.416$ & 0.391 \\
$\begin{array}{l}\text { Bleeding Volume } \\
\text { (mL) }\end{array}$ & $176.09 \pm 152.903$ & $142.69 \pm 111.543$ & 0.676 \\
$\begin{array}{l}\text { Preoperative } \\
\text { ROM }\end{array}$ & $88.9 \pm 22.9$ & $79.2 \pm 3.5$ & 0.147 \\
$\begin{array}{l}\text { Maximum } \\
\begin{array}{l}\text { Achieved }\left({ }^{\circ}\right) \\
\text { ROM difference }\end{array}\end{array}$ & $102.71 \pm 14.74$ & $106.69 \pm 13.3$ & 0.308 \\
$\begin{array}{l}\text { Presenting } \\
\text { Complications }\end{array}$ & $9.44 \pm 29.20$ & $26.02 \pm 17.56$ & 0.04 \\
\hline
\end{tabular}

The age of patients included in the study in the CR group (64.88 \pm 13.19$)$ and PS group $(67.63 \pm 8.42)$ as well as the gender distribution within the included groups in the study did not show significant difference $(p=0.391, p=0.078)$. Intraoperative bleeding volume between the two groups were also not statistically significant $(p=$ 0.676). (Table II)

Table 2. Relationship Between Bleeding Volume and Operative Time, Gender, and Age

\begin{tabular}{llll}
\multicolumn{4}{c}{ Gender, and Age } \\
Parameter & & $\begin{array}{l}\text { Bleeding } \\
\text { Volume }(\mathrm{mL})\end{array}$ & p-Value \\
\hline Operative Time (hours) & $=<3$ & $130 \pm 87$ & \multirow{2}{*}{0.102} \\
& $>3$ & $163 \pm 140$ & \\
Gender & Male & $151 \pm 147$ & 0.846 \\
& Female & $146 \pm 108$ & \\
Age & $=<65$ & $176 \pm 157$ & \\
\cline { 2 - 4 } & $>65$ & $133 \pm 89$ & 0.037 \\
\hline
\end{tabular}

The ROM analysed as an outcome for this study included the maximum ROM achieved between the two groups and the difference between the ROM prior the operation and the maximum post- operative ROM. The difference between the maximum ROM achieved between the two groups was not statistically significant ( $p=0.308)$, (Table III) whereas the ROM improvement between the two groups showed that the PS group had a significantly higher improvement in ROM (26.02 \pm 17.56) compared to the CR Group $(9.44 \pm 29.20)$ ( $p$ = 0.04). (Table IV)

Table 3. Relationship Between ROM Improvement with Operative Time,

\begin{tabular}{|c|c|c|c|}
\hline \multicolumn{4}{|c|}{ Gender, and Age } \\
\hline Parameter & & ROM & p-Value \\
\hline \multirow{2}{*}{$\begin{array}{l}\text { Pre-Operative } \\
\text { ROM }\end{array}$} & $<90^{\circ}$ & $34.1 \pm 13.9$ & \multirow[b]{2}{*}{$<0.001$} \\
\hline & $=>90^{\circ}$ & $11.6 \pm 17.8$ & \\
\hline \multirow[t]{2}{*}{ Gender } & Male & $25.3 \pm 11.6$ & \multirow[b]{2}{*}{0.81} \\
\hline & Female & $24.3 \pm 21.7$ & \\
\hline \multirow[t]{2}{*}{ Age } & $=<65$ & $24.3 \pm 20.5$ & \multirow[b]{2}{*}{0.876} \\
\hline & $>65$ & $24.9 \pm 18.5$ & \\
\hline
\end{tabular}

Table 4. Relationship Between Maximum ROM with preop ROM, gender,

\begin{tabular}{|c|c|c|c|c|}
\hline Parameter & & $\begin{array}{l}\text { Maximum } \\
\text { Achieved }\end{array}$ & ROM & p-Value \\
\hline & $<90$ & $101.2 \pm 11.7$ & & 0.001 \\
\hline \multicolumn{5}{|l|}{ Preoperative } \\
\hline ROM & $=>90$ & $109.4 \pm 13.0$ & & \\
\hline \multirow{2}{*}{\multicolumn{5}{|c|}{$107.4 \pm 13.5$}} \\
\hline & & & & \\
\hline & Female & $105.5 \pm 13.7$ & & \\
\hline & $=<65$ & $105.2 \pm 13.3$ & & 0.598 \\
\hline \multicolumn{5}{|l|}{ Age } \\
\hline & $>65$ & $106.5 \pm 13.8$ & & \\
\hline
\end{tabular}

Eleven post-operative complications were found from the 144 operated knees. The CR group had one case of deep vein thrombosis and arthrofibrosis, whereas the PS group had 4 cases of post-operative infection as well as 5 cases of deep vein thrombosis, where the difference are not statistically significant $(p=0.067)$.

\section{Discussion}

Post-operative range of motion (ROM) is a functional outcome that determines a patients' functional ability following total knee arthroplasty (TKA). A study by Kettlekamp et al determined that a knee flexion of $90^{\circ}$ is the minimum range necessary for daily activities, with about $67^{\circ}$ required during the swing phase of walking, $83^{\circ}$ 
when climbing stairs, $90^{\circ}$ when descending stairs and $93^{\circ}$ in rising from a seated position. ${ }^{18}$ Known factors that affect post-operative ROM include pre-operative ROM, BMI, and patient age, most notable of which is post-operative ROM being an indicator of intervention during the earlier part of the disease. ${ }^{19-21}$ One study by Sancheti et al demonstrated that gender was not a determining factor in ROM improvement, even though the male population showed a slightly larger gain in ROM at 6 months. ${ }^{22}$ In our study, we found that patients with a pre-operative ROM of $<90^{\circ}$ experienced a significantly greater ROM improvement than those who had a pre-operative ROM of $90^{\circ}$ or greater. We found no correlation between ROM change and gender or age.

The superiority of PS and CR prostheses for

TKA maximum ROM achieved and the improvement of ROM remains controversial. A meta-analysis by Jiang $C$. et al shows that both parameters, maximum ROM achieved and its improvement, are in favour of PS prostheses. ${ }^{23}$ Yet a study by Song S.J et al reported no notable difference in the ROM between the two prostheses, whereas another study by Kolisek F.R., et al showed a slight increase in the CR group compared to the PS group. ${ }^{24,25}$ Hence, the significance of maintaining the Posterior Cruciate Ligament is still a debatable topic. In our study, it is found that the PS group experienced a significantly higher ROM improvement compared to the $C R$ group $(p=0.04)$, with no significant difference between either groups in terms of maximum ROM achieved ( $p=0.308$ ). It is found that the preoperative ROM plays a significant role in the ROM improvement $(p<0.001)$ and maximum ROM achieved ( $p=0.001$ ), however its distribution between the two groups was not significantly different $(p=0.147)$.

Performing a CR TKR is relatively more difficult compared to its PS counterpart, however aside from functional outcomes (ROM), it has its advantages in that it involves reduced bone cuts, preserves ligamentous structures (and hence physiological function), and maintains proprioception. ${ }^{26}$ Proprioception is important for balance and postural stability, which are relevant functional outcomes. ${ }^{27}$ Evidence from studies that compared prosthetic designs have shown that $C R$ implants tend to produce superior improvement in proprioception than PS prostheses and could hence be a factor for clinicians to consider when choosing different types of prostheses. ${ }^{28}$ This is in line with existing knowledge that states that proprioceptive information originates from cruciate ligaments, which are preserved in CR TKR procedures. $^{29}$

Total knee arthroplasty is considered a major orthopaedic surgery that could potentially involve significant blood loss due to the extensive soft tissue and bone mass cut. ${ }^{13}$ Several risk factors known to have a correlation to increased blood loss during TKA, are male gender and prolonged surgical time. ${ }^{13}$ Age and BMI were not found to have any correlation with intra-operative bleeding volume. ${ }^{13}$

Additionally, it is known that intraoperative bleeding volume could predispose the patient to require transfusion. Blood transfusion has also been regarded as a parameter for perioperative complications as patients receiving transfusion during TKA are known to be susceptible to prolonged hospitalization, increased cost, and discharge to short term care. ${ }^{14}$ Previous studies have established that both female gender and older age are associated with an increased rate of transfusion in TKA patients, henceforth identifying them as independent risk factors for intra-operative blood loss, although no satisfactory explanation for this was found. ${ }^{15-17}$ In our study, we sought to quantify the need for transfusion or lack thereof in terms of intraoperative bleeding volume and found that it had a those 65 years old or younger experienced significantly greater intraoperative bleeding than those above 65 years of age, but no significant difference across different genders or operative times.

There were several limitations to this study. There were inconsistent follow-up of the patients, patients were not randomized, and there were incomplete data regarding the $\mathrm{BMI}$ due to the incomplete medical records. Additionally, the large discrepancy of sample sizes between both 
groups is also a limitation that might have influenced our statistical analyses. Despite these limitations, the report analyses other possible confounding factors as objectively as possible.

\section{Conclusions}

In summary, our findings show that PS prostheses was superior to CR in terms of ROM improvement with both groups having similar maximum ROM achieved. Additionally, age of $<65$ years was a predictor for increased intraoperative bleeding volume, and that a pre-operative ROM of $<90$ was a predictor for better improved postoperative ROM.

\section{Conflict of Interest}

The authors affirm no conflict of interest in this study

\section{Acknowledgements}

The authors of this study would like to express their deepest gratitude for the aid they have received from the department of Orthopaedics and Traumatology, Cipto Mangunkusumo Hospital, and department of medical records, Saint Carolus Hospital. This research did not receive any grants, and none of the authors declared any competing interests.

\section{References}

1. American Joint Replacement Registry 2018 Annual Report. Illinois: American Joint Replacement Registry; 2018 [cited 15 December 2018].

2. Lavernia CJ, Guzman JF, Gachupin-Garcia A. Cost effectiveness and quality of life in knee arthroplasty. Clin Orthop. 1997 Dec;(345):134-9.

3. Inacio MCS, Paxton EW, Graves SE, Namba RS, Nemes S. Projected increase in total knee arthroplasty in the United States - an alternative projection model. Osteoarthritis Cartilage. 2017;25(11):1797-803.

4. Pagnano MW, Cushner FD, Scott WN. Role of the posterior cruciate ligament in total knee arthroplasty. J Am Acad Orthop Surg. 1998 Jun;6(3):176-87.

5. Andriacchi TP, Galante JO. Retention of the posterior cruciate in total knee arthroplasty. J Arthroplasty. 1988;3 Suppl:S13-19.

6. Conditt MA, Noble PC, Bertolusso $R$, Woody J, Parsley BS. The PCL significantly affects the functional outcome of total knee arthroplasty. J Arthroplasty. 2004 Oct;19(7 Suppl 2):107-12.

7. Victor J, Banks S, Bellemans J. Kinematics of posterior cruciate ligament-retaining and substituting total knee arthroplasty: a prospective randomised outcome study. J Bone Joint Surg Br. 2005 May;87(5):646-55.

8. Verra WC, Boom LGH van den, Jacobs WCH, Schoones JW, Wymenga AB, Nelissen RGHH. Similar outcome after retention or sacrifice of the posterior cruciate ligament in total knee arthroplasty. Acta Orthop. 2015 Apr;86(2):195201.

9. Luo S, Zhao JM, Su W, Li X, Dong G. Posterior cruciate substituting versus posterior cruciate retaining total knee arthroplasty prostheses: a meta-analysis. The Knee. 2012 Aug;19(4):246-52.

10. Maradit Kremers $\mathrm{H}$, Larson DR, Crowson CS, Kremers WK, Washington RE, Steiner CA, et al. Prevalence of Total Hip and Knee Replacement in the United States. J Bone Joint Surg Am. 2015 Sep 2;97(17):1386-97.

11. Kurtz SM, Lau E, Ong K, Zhao K, Kelly M, Bozic KJ. Future young patient demand for primary and revision joint replacement: national projections from 2010 to 2030. Clin Orthop. 2009 Oct;467(10):2606-12.

12. Cram P, Lu X, Kates SL, Singh JA, Li Y, Wolf $B R$. Total knee arthroplasty volume, utilization, and outcomes among Medicare beneficiaries, 1991-2010. JAMA. 2012 Sep 26;308(12):1227-36.

13. Prasad N, Padmanabhan V, Mullaji A. Blood loss in total knee arthroplasty: an analysis of risk factors. Int Orthop. 2007 Feb;31(1):39-44.

14. Mistry JB, Gwam CU, Naziri Q, Pivec R, Abraham R, Mont MA, et al. Are Allogeneic Transfusions Decreasing in Total Knee Arthroplasty Patients? National Inpatient Sample 2009-2013. J Arthroplasty. 2018;33(6):1705-12. 
15. Slover J, Lavery JA, Schwarzkopf R, lorio R, Bosco J, Gold HT. Incidence and Risk Factors for Blood Transfusion in Total Joint Arthroplasty: Analysis of a Statewide Database. J Arthroplasty [Internet]. 2017 Sep [cited 2020 Jun 14];32(9):2684-2687.e1. Available from: https://linkinghub.elsevier.com/retrieve/pii/S088 3540317303893

16. To J, Sinha R, Kim SW, Robinson K, Kearney $B$, Howie $D$, et al. Predicting Perioperative Transfusion in Elective Hip and Knee Arthroplasty: A Validated Predictive Model. Anesthesiology. 2017;127(2):317-25.

17. Sizer SC, Cherian JJ, Elmallah RDK, Pierce TP, Beaver WB, Mont MA. Predicting Blood Loss in Total Knee and Hip Arthroplasty. Orthop Clin North Am. 2015 Oct;46(4):445-59.

18. Kettelkamp DB, Johnson RJ, Smidt GL, Chao EY, Walker M. An electrogoniometric study of knee motion in normal gait. J Bone Joint Surg Am. 1970 Jun;52(4):775-90.

19. Laubenthal KN, Smidt GL, Kettelkamp DB. A quantitative analysis of knee motion during activities of daily living. Phys Ther. 1972 Jan;52(1):34-43.

20. Gatha NM, Clarke HD, Fuchs R, Scuderi GR, Insall JN. Factors affecting postoperative range of motion after total knee arthroplasty. J Knee Surg. 2004 Oct;17(4):196-202.

21. Farahini $H$, Moghtadaei $M$, Bagheri $A$, Akbarian $E$. Factors influencing range of motion after total knee arthroplasty. Iran Red Crescent Med J. 2012 Jul;14(7):417-21.

22. Sancheti KH, Sancheti PK, Shyam AK, Joshi $\mathrm{R}$, Patil $\mathrm{K}$, Jain $\mathrm{A}$. Factors affecting range of motion in total knee arthroplasty using high flexion prosthesis: A prospective study. Indian J Orthop. 2013 Jan;47(1):50-6.

23. Jiang C, Liu Z, Wang Y, Bian Y, Feng B, Weng $X$. Posterior Cruciate Ligament Retention versus Posterior Stabilization for Total Knee Arthroplasty: A Meta-Analysis. PloS One. 2016;11(1):e0147865. 24. Song SJ, Park CH, Bae DK. What to Know for Selecting Cruciate-Retaining or PosteriorStabilized Total Knee Arthroplasty. Clin Orthop Surg. 2019 Jun;11(2):142-50.
25. Kolisek FR, McGrath MS, Marker DR, Jessup N, Seyler TM, Mont MA, et al. Posteriorstabilized versus posterior cruciate ligamentretaining total knee arthroplasty. lowa Orthop J. 2009;29:23-7.

26. Calvisi V, Paglia A, Ciprietti N, Goderecci R. Cruciate-Retaining Total Knee Arthroplasty. In: Zorzi AR, Miranda JB de, editors. Primary Total Knee Arthroplasty [Internet]. InTech; 2018 [cited 2020 Jul 28]. Available from: http://www.intechopen.com/books/primarytotal-knee-arthroplasty/cruciate-retaining-totalknee-arthroplasty

27. Moutzouri M, Gleeson N, Billis E, Tsepis E, Panoutsopoulou I, Gliatis J. The effect of total knee arthroplasty on patients' balance and incidence of falls: a systematic review. Knee Surg Sports Traumatol Arthrosc Off J ESSKA. 2017 Nov;25(11):3439-51.

28. Warren PJ, Olanlokun TK, Cobb AG, Bentley G. Proprioception after knee arthroplasty. The influence of prosthetic design. Clin Orthop. 1993 Dec;(297):182-7.

29. Johansson $\mathrm{H}$, Sjölander P, Sojka P. Activity in receptor afferents from the anterior cruciate ligament evokes reflex effects on fusimotor neurones. Neurosci Res. 1990 Apr;8(1):54-9. 